\title{
Assessment of the proportion and the factors associated with partner and family based index case HIV testing in Woliso town, Oromia, Ethiopia: a cross-sectional study
}

Teka Haile ( $\nabla$ tekahaile22@gmail.com )

Shanxi Center for Disease Control and Prevention https://orcid.org/0000-0003-1234-2385

Hanna Gulema

Addis Continental Institute of Public Health

Research article

Keywords: HIV testing, partner, children, Woliso, Ethiopia

Posted Date: May 6th, 2020

DOI: https://doi.org/10.21203/rs.3.rs-24186/v1

License: (a) (1) This work is licensed under a Creative Commons Attribution 4.0 International License.

Read Full License 


\section{Abstract}

Background: Despite the enormous expansion of HIV testing services (HTS), an estimated $40 \%$ of people with HIV infection remain undiagnosed. In Ethiopia, the current working UNAIDS spectrum estimate for PLHIV is 649,264 , of the estimated PLHIV, only about $72 \%$ know their status.

Methods: A facility based cross-sectional study design with internal comparison was conducted among randomly selected 346 people currently on ART in Woliso town. Data entry carried out by Epi Info ${ }^{\text {TM }}$ version 7.2.3.1 and analyzed using SPSS version 21.0 statistical software for Windows.

Results: Among 345 study participants, 333 (96.5\%) with $95 \% \mathrm{Cl}(94.5$ - 98.3) of index cases have tested families. The odds of HIV testing were 7.22 times higher among those who disclosed their HIV status (AOR=7.22 95\% Cl: $1.45,35.82$ ) compared to those who did not disclosed. Those who have stayed $<12$ months on ART are $87 \%$ less likely to have tested families (AOR=0.13 95\% Cl: $0.03,0.63$ ) compared to those who stayed $\geq 12$ months on ART.

Conclusion: this study finding shows that higher proportions of families of index cases have been tested for HIV. It also shows that partner and family based index case HIV testing has significant association with HIV status disclosure of index cases and the length of the duration that the index cases stayed on ART. It is essential to sustain the platform of partner and family based index case HIV testing service through strengthening disclosure counselling and assisting HIV status disclosure in health facilities with fully trained provider and qualified health providers. It also suggests the need to focus on those who received ART for less than 12 months duration and communicate on the timing of HIV testing for HIV negative families with ongoing risk of acquiring HIV.

\section{Background}

According to the EDHS 2016, the national HIV prevalence of Ethiopia is 0.9\%. Furthermore, the 2017 HIV prevalence in regions ranges from 0.16-4.34\% (1-4). Based on 2018 spectrum, the 2017 ART coverage for adults (age $>15$ ) has reached $75 \%$ but the coverage remains low $(34 \%)$ for children living with HIV (2). Almost half of HIV infected patients enrolled in ART had untested family members, many of whom were children (5). Family testing is an index case finding strategy to identify family members with unknown HIV status (6). Index case HIV testing strategy uses a known HIV-infected person receiving HIV care as an index reference to target partners for HIV testing $(5,7)$. In 2014, UNAIDS set the goal to end the AIDS epidemic by 2030 and also stated that worldwide $95 \%$ of all people living with HIV should be aware of their HIV status while an estimated $40 \%$ still remain undiagnosed (8). HIV partner notification enables to identify people with undiagnosed HIV infection $(9,10)$ and linking clients to ART $(11)$.

In 2017, the UNAIDS estimated that 75\% of PLHIV were aware of their HIV status, leaving 9.4 million persons with undiagnosed (12). Assisted partner services are rarely available in sub Saharan Africa (13) even though pediatric HIV testing barriers are distinct from adult barriers (14). However, partner notification strategies must be feasible in healthcare setting and acceptable to the population $(2,15)$ as 
well to children's HIV testing during the routine activities (16). Healthcare settings screen broadly for HIV use social network and partner testing to select high-risk individuals based on their contacts (17).

Efforts should be made to pursue partner notification to identify people living with HIV infection (18). In Tanzania, 249 partners reaching the facilities, 96\% tested for HIV, 148 (61.9\%) tested HIV positive, and $104(70.3 \%)$ of partners testing positive were enrolled into ART (19). In Kenya, for each index patient, 61\% of family members identified and tested were children (20). In Zimbabwe, the mean monthly HIV positivity rate from index testing (32.6\%) was significantly higher than that achieved in other HIV testing modalities (21).

The South African PMTCT programs had reduced perinatal HIV transmission at 6 weeks of age to $2.7 \%$ and timely maternal diagnosis enables PMTCT uptake to improve infant outcomes (22). Integrating HIV testing into all pediatric health services can assist in identifying HIV infected children (23).

In Ethiopia, the HIV diagnosis is affected by different factors. From study in Harar, clients aged 3544 years were less likely to accept PITC services than those whose ages were 15-24 years (AOR: 0.17 [0.07-0.41]) (24). In Northern Ethiopia, subjects who initiated by friends, families and other socials to undertake HIV testing (AOR $=0.65 ; 95 \% \mathrm{Cl}=0.29,1.48)(25)$. HIV stigma has an important role in the spread of the AIDS epidemic. Fear of being identified as having HIV may discourage a person from getting tested (26). In Awi Zone, Northwest Ethiopia, respondents unwilling to disclose themselves utilized VCT services about $38 \%$ less than their counterparts (AOR: $0.62 ; 95 \% \mathrm{Cl}: 0.44,0.88)(27)$. Many children living with HIV in resource-limited settings remain undiagnosed and at risk for HIV-related mortality and morbidity (28) and several factors were associated with non-testing of partners and there remains numerous serious challenges to reaching full global epidemic control (95-95-95) $(29,30)$.

Financial incentives have overcome financial barriers to identify HIV-infected children in other populations by offsetting direct and indirect costs (31). In Zambia, emotional intimate partner violence and HIV status disclosure to the male partner, may play an important role in maternal uptake of early infant HIV testing (32).

In Peru, out of 1586 PLWH, 171 had a previously enrolled partner, HIV status of the partner was reported as unknown in 571 (40\%), seronegative in $325(23 \%)$ and seropositive in $519(37 \%)$. Out of 896 partners in the unknown/seronegative group, 72 (8\%) had HIV testing, 42/72 (58\%) tested within three months of index case enrollment (33).

According to study in Assosa town, those who planned to disclose their test results from their husbands had higher odd of acceptance (AOR 14.85; 95\% Cl 4.60-47.94) than who secreted (34). While, in Hawassa, majority of ANC clients, $84.1 \%$ (95\% Cl: $80.6-87.2 \%)$, of those accepted the HCT (35). Similarly, in Jimma town, non-disclosure agreement $36 \%$ less likely [AOR $(95 \% \mathrm{Cl})=0.74(0.58-0.93)](36)$.

An estimated $30 \%$ of HIV cases in the EU are also not aware of their HIV status (37). In Georgia during 2013 revealed that $82 \%$ of PLHIV knew their diagnosis (38). 
This health facility based cross-sectional study with internal comparison was aimed to assess the proportion and the factors associated with partner and family based index case HIV testing services in Woliso town, Oromia, Ethiopia.

\section{Methods}

\section{Study Setting}

The study was conducted in Woliso town which is located in Oromia Regional National State 114KM from Addis Ababa on the road from Addis Ababa to Jimma. It has a latitude and longitude of $8^{\circ} 32^{\prime} \mathrm{N}$ $37^{\circ} 58^{\prime} \mathrm{E}$ with an elevation of 2063 meters above sea level (39). The population of the town is 64,681 of which $51 \%$ are females and the rest are males. In 2015 the town was selected as one of the twenty towns with high burden of HIV in Ethiopia and one of the ten towns with high burden of HIV in Oromia. At the end of September 2019 the town has 2,376 PLWHIV who are currently on ART. The town has three health facilities with two ART site and one PMTCT site.

\section{Study design}

Facility based cross sectional study with internal comparison was conducted to assess the proportion and the factors associated with partner and family based index case HIV testing services in Woliso town, Oromia, Ethiopia.

\section{Source And Study Population:}

The source population of the study is all 2,376 people living with HIV (PLWHIV) in Woliso Town who are currently receiving anti-retroviral therapy (ART) in Woliso Town health facilities.

The study population was those clients currently receiving anti-retroviral therapy (ART) who are eligible for Partner and Family Based Index Case HIV Testing (P\&FBICT) service during the study period. The study was conducted among eligible clients selected by systematic random sampling.

\section{Inclusion criteria}

All people living with HIV (PLWHIV) in Woliso Town who are currently receiving anti-retroviral therapy (ART) and eligible for Partner and Family Based Index Case HIV Testing (P\&FBICT) service during the data collection period in Woliso Town health facilities.

\section{Exclusion criteria}


Eligible people living with HIV who are seriously ill during data collection period or who are physically unfit for interview.

\section{Sample Size:}

The sample size for people living with HIV who are currently on ART and eligible for Partner and Family Based Index Case HIV Testing (P\&FBICT) services were determined using single proportion formula of initial sample size $\left[n=(Z \alpha / 2)^{2} p(1-p) / d^{2}\right](40)$ by considering the following assumptions: $n=(Z \alpha / 2)^{2} p(1-$ p) $/ d^{2}, 95 \%$ confidence level $(Z \alpha / 2=1.96)$, assuming that $50 \%$ of eligible clients have tested families $(P=$ $0.5), 5 \%$ marginal error between the sample $(d=0.05)$. The sample size for the first objective, since the total number of population is less than $10,000(\mathrm{~N}=1563)$ and relatively small population

$$
\begin{aligned}
& \mathrm{n}=\frac{(Z \propto / 2)^{2} p(1-\mathrm{p})}{\mathrm{d}^{2}} \\
& \mathrm{n}=\frac{(1.96)^{2} 0.5(1-0.5)}{(0.05)^{2}}=384
\end{aligned}
$$

Since the total number of population is less than $10,000(N=1563)$ and relatively small population the sample size will be

$$
\mathrm{n} \text { final }=\frac{\mathrm{n}}{1+\underline{\mathrm{n}}}=\frac{384}{1+\underline{\mathrm{n}} \underline{\mathrm{N}}}=308
$$

But, from Epi Info Stat Calculator, the final sample size for the first objective at two-sided confidence level of $95 \%, 80 \%$ power, ratio of unexposed to exposed equal to $1,70 \%$ outcome in unexposed group, risk ratio (0.78), OR (0.52) and $54.8 \%$ outcome in exposed group was 346.

The sample size for the second objective was calculated using Epi Info Stat Calculator for un matched case control using different associated factors included in the conceptual framework (41). Since the sample size for the second objective is less than that of the first objective, 346 study participants were included in the study.

\section{Sampling procedures}

The sample was drawn from people living with HIV in Woliso Town who are currently receiving antiretroviral therapy (ART) and eligible for Partner and Family Based Index Case HIV Testing service during the study period. 
The total sample size was 346 which was generated using systematic random sampling method from line list of eligible PLHIV for Partner and Family Based Index Case HIV Testing (P\&FBICT) service and which is small population size that is $(N=1563)$ because the total population of this study population is $\mathrm{n}<10,000$. Then, 346 eligible for Partner and Family Based Index Case HIV Testing (P\&FBICT) during the study period were included in order to approach study subjects during data collection period in two public health facilities in Woliso Town based on their population proportion.

To get the interval value $(K)$ the study population was divided for study subjects $(\mathrm{N} / \mathrm{n})$. By dividing 594 eligible clients expected to come monthly to 226 clients that was taken from St Luke Hospital which is $(594 / 226=2.6 \sim 3)$, from Woliso Health Center is $(336 / 120=2.8 \sim 3)$ then one was selected using lottery method and the number selected was the first number to start. Thus, every 3rd clients were selected to get all study subjects. Likewise, the proportional allocation for distribution of study population was 226 (65.3\%) for St. Luke Hospital and 120 (34.7\%) for Woliso Health Center. By taking the study population of $\mathrm{N}=1563$ (for St. Luke hospital and Woliso Health center) and $\mathrm{n}=346$ (the calculated sample size).

\section{Data collection procedures}

Structured questionnaire was used to capture data relevant to the study's objective and research questions. The questionnaire is formulated to capture the Proportion and the Factors Associated with Partner and Family Based Index Case HIV Testing (P\&FBICT) services. The data was collected by directly interviewing eligible individuals and reviewing some records as secondary data. The questionnaire is initially prepared in English and translated into the local languages, Amharic and Afan Oromo, and then it was translated back to English to check the comprehension and consistency.

Information generated through interview was entered into Epi Info ${ }^{\text {TM }}$ version 7.2.3.1 and exported to SPSS version 21.0 software for analysis. The data was collected at health facility during the time period from December 2019 to January 2020.

To assure the quality of the data appropriately designed questionnaire was pre-tested on 5 percent of the sample size, in health facility outside the study area. The principal investigator trained the data collectors. During the data collection, principal investigator supervised over the data collection process. Data collected was reviewed and checked for completeness and consistency of the response.

\section{Operational definitions}

Operational definitions are

\section{Eligible clients}

Those who have partner, or have children $<15$ years of age, or have both partner and have children $<$ 15 years of age. 


\section{Index client}

individual newly diagnosed as HIV positive and/or HIV positive who is already enrolled in HIV care.

\section{Partner and Family Based Index Case HIV Testing service}

HIV testing and counseling for partner, children of people living with HIV who are aged $<15$ years, and parents of index child.

\section{Families tested}

either partner or children $<15$ years of age tested for HIV.

\section{Data Management}

Data collected from the assessment were checked for consistency to assess the data quality. The data were entered into Epi Info ${ }^{\text {TM }}$ version 7.2.3.1 and exported to SPSS version 21.0 software for analysis.

\section{Data Analysis procedures}

Data was quantitatively analyzed and it was done by running frequencies, percentages and cross tabulation of categorical data. Binary logistic regression was used to examine association between selected exposure variables and outcome variable HIV testing. All variables with $p<0.2$, in bivariate analysis were entered into multivariate analysis to identify factors independently associated with HIV testing and for controlling some potential confounders. The significance of Odds Ratios was determined with $95 \% \mathrm{Cl}$ and $\mathrm{p}<0.05$.

\section{Results}

\section{Socio-demographic characteristics of PLWHIV}

The response rate of this study was found to be 345 (99.7\%). The mean ( \pm SD) age of people living with HIV who participated in this study was 39.31 years $( \pm 8.03)$. Among 345 study participants, the majority, $219(63.5 \%)$ of them were females, while the rest $126(36.5 \%)$ were males. Among 345 study participants 247 (71.6\%) were married, 52 (15.1\%) were divorced/separated, while 46 (13.3\%) were widowed.

The majority of the study participants were from urban area $209(60.6 \%)$ and the rest $136(39.4 \%)$ were from rural area. The majority of study participants were other unemployed $142(41.2 \%)$ and farmers were 94 (27.2\%), while merchants and government employees were 74 (21.4\%) and 35 (10.1\%), respectively. Regarding their monthly income level 180 (52.2\%) reported greater than or equal to 1,000 ETB, while 165 $(47.8 \%)$ reported less than 1,000 ETB (Table 1 ). 


\section{Health and Family related factors of people living with HIV}

Majority of the study participants, 333 (96.5\%) with 95\% Cl (94.5-98.3) have families tested for HIV. Majority of them 319 (92.5\%) were on ART for greater than or equal to 12 months and $26(7.5 \%)$ of them were on ART for less than 12 months duration. Around 324 (93.9\%) have disclosed their HIV status, while 21 (6.1\%) did not disclosed their HIV status. Among the study participants 247 (71.6\%) have partner, while $98(28.4 \%)$ do not have partner, and the majority 278 (80.6\%) have children less than 15 years of age (Table 2).

Among 247 study participants who have partner, 61 (24.7\%) are HIV negatives and 10 (4.0\%) have partners with unknown HIV status. Among 278 study participants who have children $<15$ years of age, 19 $(6.8 \%)$ have at least one child with unknown HIV status and 10 (3.6\%) have two children and above with unknown HIV status (Table 2).

\section{Knowledge and other factors related with P\&FBICT}

The majority of the study participants $282(81.7 \%)$ have poor knowledge on the perceived benefits and the facilitators of Partner and Family Based Index Case HIV testing services and 57 (16.5\%) have moderate knowledge. Around $80(23.2 \%)$ of the study participants have ever experienced intimate partner violence. Regarding HIV related stigma, around 88 (25.5\%) of the study participants agreed that fear of stigma is barrier for family HIV testing (Table 3 ).

\section{Factors Associated with Partner and Family Based Index Case HIV Testing services}

In multivariate analysis, HIV status disclosure and duration of ART were significantly associated with partner and family based index case HIV testing. The odds of partner and family based index case HIV testing was 7.22 times higher among study participants who have disclosed their HIV status (AOR $=7.22$ $95 \% \mathrm{Cl}: 1.45,35.82)$ compared to those who did not disclosed. Those participants who have stayed $<12$ months on ART are $87 \%$ less likely to have families for partner and family based index case HIV testing $(A O R=0.1395 \% \mathrm{Cl}: 0.03,0.63)$ compared to those who stayed $\geq 12$ months on ART (Table 4). 
Table 1

Socio-demographic characteristics of PLHIV, Woliso town, Oromia, Ethiopia $(\mathrm{n}=345)$.

\begin{tabular}{|c|c|c|}
\hline Age & Frequency & Percentage \\
\hline$<30$ & 29 & 8.4 \\
\hline $30-39$ & 168 & 48.7 \\
\hline $40-49$ & 111 & 32.2 \\
\hline$\geq 50$ & 37 & 10.7 \\
\hline \multicolumn{3}{|l|}{ Sex } \\
\hline Male & 126 & 36.5 \\
\hline Female & 219 & 63.5 \\
\hline \multicolumn{3}{|l|}{ Religion } \\
\hline Orthodox & 186 & 53.9 \\
\hline Protestant & 134 & 38.8 \\
\hline Muslim & 24 & 7.0 \\
\hline Catholic & 1 & 0.3 \\
\hline \multicolumn{3}{|l|}{ Educational level } \\
\hline No education & 88 & 25.5 \\
\hline Primary & 172 & 49.9 \\
\hline Secondary & 67 & 19.4 \\
\hline College and above & 18 & 5.2 \\
\hline \multicolumn{3}{|l|}{ Ethnicity } \\
\hline Oromo & 277 & 80.3 \\
\hline Amhara & 37 & 10.7 \\
\hline Gurage & 26 & 7.5 \\
\hline Tigre & 2 & 0.6 \\
\hline Others (Kambata, Wolayita) & 3 & 0.9 \\
\hline \multicolumn{3}{|l|}{ Marital status } \\
\hline Married & 247 & 71.6 \\
\hline Divorced/Separated & 52 & 15.1 \\
\hline
\end{tabular}




\begin{tabular}{|lll|}
\hline \multicolumn{1}{|l}{ Age } & Frequency & Percentage \\
\hline Widowed & 46 & 13.3 \\
\hline Urban & & \\
\hline Rural & 209 & 60.6 \\
Occupational category & 136 & 39.4 \\
\hline Government employee & 35 & 10.1 \\
\hline Merchant & 74 & 21.4 \\
\hline Farmer & 94 & 27.2 \\
\hline Other unemployed & 142 & 41.2 \\
\hline Monthly income level & & \\
\hline$<1,000$ ETB & 165 & 47.8 \\
\hline$\geq 1,000$ ETB & 180 & 52.2 \\
\hline Note:-Others in Ethnicity includes Wolayita $=2$, Kambata $=1$. \\
\hline
\end{tabular}


Table 2

Health and Family related factors of PLHIV, Woliso town, Oromia, Ethiopia, 2020.

\begin{tabular}{|c|c|c|}
\hline Months on ART & Frequency & Percentage \\
\hline$<12$ months & 26 & 7.5 \\
\hline$\geq 12$ months & 319 & 92.5 \\
\hline \multicolumn{3}{|l|}{ HIV status disclosure } \\
\hline Disclosed & 324 & 93.9 \\
\hline Not disclosed & 21 & 6.1 \\
\hline \multicolumn{3}{|l|}{ To whom disclosed } \\
\hline Partner & 243 & 75.0 \\
\hline Own children & 49 & 15.1 \\
\hline Brothers/sisters & 15 & 4.6 \\
\hline Parents & 13 & 4.0 \\
\hline Others (Neighbours, Friends) & 4 & 1.2 \\
\hline \multicolumn{3}{|l|}{ Have partner } \\
\hline Yes & 247 & 71.6 \\
\hline No & 98 & 28.4 \\
\hline \multicolumn{3}{|l|}{ Have children $<15$ years } \\
\hline Yes & 278 & 80.6 \\
\hline No & 67 & 19.4 \\
\hline \multicolumn{3}{|l|}{ Families tested for HIV } \\
\hline Yes & 333 & 96.5 \\
\hline No & 12 & 3.5 \\
\hline \multicolumn{3}{|c|}{ Have children $<15$ years who are HIV positive } \\
\hline no child & 221 & 0.9 \\
\hline at least one child & 31 & 0.1 \\
\hline two children and above & 6 & 0.0 \\
\hline \multicolumn{3}{|c|}{ Have children $<15$ years who are HIV negative } \\
\hline one child and blow & 119 & 0.5 \\
\hline two children and above & 139 & 0.5 \\
\hline
\end{tabular}




\begin{tabular}{|cll|}
\hline Months on ART & Frequency & Percentage \\
\hline Have children < 15 years with unknown HIV status & & \\
\hline no child & 249 & 0.9 \\
\hline at least one child & 19 & 0.1 \\
\hline two children and above & 10 & 0.0 \\
\hline Partner HIV status & & \\
\hline HIV positive & 176 & 0.7 \\
\hline HIV negative & 61 & 0.2 \\
\hline Unknown HIV status & 10 & 0.04 \\
\hline
\end{tabular}


Table 3

Knowledge and Other factors related with Partner and Family Based Index case HIV testing, Woliso town, Oromia, Ethiopia, 2020.

\section{Knowledge on P\&FBICT}

Poor

Moderate

Good

Experienced Intimate Partner Violence

No

Yes

Type of Intimate Partner Violence experienced

Hit, kicked, slapped, physically hurt

Threatened to hurt

Fear of Stigma

No

Yes

Preferred referral means

Client referral

Provider referral

Dual referral

Contractual referral

Preferred place for HIV testing

Home based

Community based

Health facility based

Preferred time for HIV testing in health facilities

Regular work hours

Evening

Weekends/holidays

Preferred time for HIV testing in health facilities
265

80

48

32

257

88

74.5

25.5

40.0

23.2

16.5

1.7

76.8

\section{0}

0.0

40.0

60.3

13.9

4.6

16

21.2

$73 \quad 21.2$

6.7

24

7.0

298

86.4

Evening

Weekends/holidays

139

46.6

5

1.7

154

51.7 
Note: The modified Bloom's scale of HIV/AIDS knowledge adopted from Nyasinde Mujumali's KAP study was used and the cutoff points for the score was $75-100 \%, 50-74 \%$, and $<50 \%$ placed the respondents in good, moderate, and poor knowledge groups on the benefits and facilitators of P\&FBICT services, respectively.

\section{Discussion}

HIV testing is an essential gateway to treatment and care, through provision of ART and counseling on avoiding risky sexual behavior which is a key part of preventing transmission. In its 95-95-95 targets, UNAIDS has called for $95 \%$ of PLHIV to know their status, $95 \%$ of those who know their status to receive ART, and $95 \%$ of ART recipients to achieve viral suppression by 2030 (30).

This study finding shows that higher proportion of families of index cases have been tested for HIV. It also shows that partner and family based index case HIV testing has significant association with HIV status disclosure of index cases and also significantly associated with the length of the duration that the index cases stayed on ART.

In this study, about more than nine in ten (96.5\%) with 95\% Cl (94.5-98.3) of index cases have brought either partner or children less than 15 years of age for partner and family based index case HIV testing. This result is relatively similar to study in Tanzania which was $96 \%$ (19). However, it was relatively lower than study in Abuja, Nigeria which was $98.7 \%$ (42). On the other hand, higher than study in Hawassa, Kenya and India, which was $84.1 \%, 61 \%$ and $77 \%$, respectively $(20,29,35)$. Likewise, it was higher than studies conducted in Harar, Barcelona, Peru and Burkina Faso, which was $70.6 \%, 70.8 \%, 60 \%$ and $88.1 \%$, respectively $(16,24,33,37)$. It is also higher than study in Gondar and Southern Ethiopia, which was $81.7 \%$ and $68.8 \%$, respectively $(43,44)$.

Thus, the finding of this study implies that there is already an encouraging platform for index case HIV testing, specially assisted partner HIV testing services in Sub Saharan Africa and this could serve as aspiring board to achieve full scale partner and family based index case HIV testing service in Woliso town and other similar areas.

This study demonstrated that the odds of family HIV testing were found to be higher among index cases who have disclosed their HIV status (AOR $=7.2295 \% \mathrm{Cl}: 1.45,35.82)$ compared to those who have not disclosed their HIV status.

This finding is consistent with study in Assosa town, the odds

of acceptance of provider-initiated HIV testing was higher among those who planned to disclose their test results from their husbands ( $\mathrm{AOR}=14.85 ; 95 \% \mathrm{Cl}: 4.60-47.94)$ than those who secreted (34).

It is also similar to study in Gondar which shows that planning of HIV test disclosure to male partners have higher odds of HIV testing (AOR: 7.81, 95\% Cl: 3.17-13.14) compared to their counterparts (43). 
Table 4

Factors Associated with Partner and Family Based Index Case HIV Testing services, Woliso town, Oromia, Ethiopia, 2020.

\begin{tabular}{|c|c|c|c|c|}
\hline \multirow[t]{2}{*}{ Variables } & \multicolumn{2}{|c|}{ HIV Testing } & \multirow[t]{2}{*}{ COR (95\% Cl) } & \multirow[t]{2}{*}{ AOR (95\% Cl) } \\
\hline & Yes & No & & \\
\hline \multicolumn{5}{|l|}{ Sex } \\
\hline Male & 125 & 1 & $6.61(0.84,51.82)$ & $5.21(0.55,49.76)$ \\
\hline Female & 208 & 11 & 1 & 1 \\
\hline \multicolumn{5}{|l|}{ Marital status } \\
\hline Married & 244 & 3 & 1 & 1 \\
\hline Divorced/ Separated & 44 & 8 & $0.07(0.02,0.27)^{\star \star \star}$ & $0.21(0.04,1.06)$ \\
\hline Widowed & 45 & 1 & $0.55(0.06,5.44)$ & $1.14(0.09,13.74)$ \\
\hline \multicolumn{5}{|l|}{ Months on ART } \\
\hline$<12$ months & 21 & 5 & $0.09(0.03,0.32)^{\star \star \star}$ & $0.13(0.03,0.63) *$ \\
\hline$\geq 12$ months & 312 & 7 & 1 & 1 \\
\hline \multicolumn{5}{|l|}{ HIV disclosure status } \\
\hline Not disclosed & 15 & 6 & 1 & 1 \\
\hline Disclosed & 318 & 6 & $21.2(6.11,73.59)^{\star \star \star}$ & $7.22(1.45,35.82)^{\star}$ \\
\hline \multicolumn{5}{|c|}{$\begin{array}{l}\text { * Statistically significant }(p=0.01-0.05) \text {, ** Strong statistical significance }(p=0.001-0.01) \text {, } * \star * \text { Very } \\
\text { strong statistical significance }(p<0.001) \text {. Statistical fitness was checked with Hosmer and Lemeshow } \\
\text { test }(p<0.75) \text {. }\end{array}$} \\
\hline
\end{tabular}

This might be due to frequent counseling from the providers during their subsequent visits both for status disclosure and family testing which are expected in HIV preventive packages (2). Similarly, study in Jimma town, shows that the acceptance of provider-initiated HIV testing was $14 \%$ less likely among nondisclosures (AOR $=0.86 ; 95 \% \mathrm{Cl}$ : 0.69-0.99) (36). Another study conducted in Awi Zone, shows that those unwilling to disclose themselves utilized HCT services $38 \%$ less than their counterparts (AOR: $0.62 ; 95 \%$ Cl: $0.44,0.88)(27)$. Another consistent study in Zambia shows, HIV status disclosure to the male partner has higher odds to get families tested (AOR $=13.73,95 \% \mathrm{Cl}: 3.59-52.49, \mathrm{p}<0.001)(32)$.

This study result also showed that index cases those stayed on ART for $<12$ months were significantly $87 \%$ less likely to bring their partner and children less than 15 years of age for HIV testing (AOR $=0.13$ $95 \% \mathrm{Cl}: 0.03,0.63)$ compared to those who stayed on ART for $\geq 12$ months. In Ethiopian context, it is expected that the longer time index cases stayed on ART, the higher chance to get families tested (2). This finding is consistent with the findings from a mixed methods evaluation on the HIV basic care package 
including family HIV testing in Kenya and Uganda, the HIV basic care package receipt was significantly associated with using ART [OR $=1.1,95 \% \mathrm{Cl}: 1.0-1.1]$ (45).

The results of this study should be interpreted within several limitations. First, it is cross-sectional and cannot establish causality or the timing of HIV testing. Second, HIV status disclosure is based on selfreport, which can be vulnerable to recall and social desirability biases. The sample is also nonrepresentative and health facility based, limiting the generalizability of the findings. This study may also have selection bias because all participants were coming for ART, which may not be representative of all partners and children less than 15 years of age in needing partner and family based index case HIV testing. We did not measure the level of communication among the couple or partner and their matured children, which may affect the acceptance HIV testing. Third, the interview was conducted based on the client's perspectives, which may not reflect the whole picture of HIV testing service. Therefore, institutional related characteristics should be included and evaluated in the future study.

\section{Conclusion}

In conclusion, this study finding shows that higher proportions of families of index cases have been tested for HIV. It also shows that partner and family based index case HIV testing has significant association with HIV status disclosure of index cases and also significantly associated with the length of the duration that the index cases stayed on ART. It is essential to sustain the platform of partner and family based index case HIV testing service through strengthening disclosure counselling and assisting HIV status disclosure in health facilities with fully trained provider and qualified health providers. It also suggests the need to focus on those who received ART for less than 12 months duration.

\section{Abbreviations}

AIDS: Acquired Immunodeficiency Syndrome, AOR: Adjusted Odds Ratio, ART: Anti-Retroviral Therapy, Cl: Confidence Interval, COR: Crude Odds Ratio, EDHS: Ethiopian Demographic and Health Survey, ETB: Ethiopian Birr, FMOH: Federal Ministry of Health, HIV: Human Immunodeficiency Virus, HTS: HIV testing services, P\&FBICT: Partner and Family Based Index Case testing, PLHIV: People Living with HIV, PMTCT: Prevention of Mother to Child Transmission, UNAIDS: The Joint United Nations Program on HIV/AIDS.

\section{Declarations}

\section{Ethics approval and consent to participate}

Ethical clearance was obtained from the Research Ethical Review Committee of the Addis Continental Institute of Public Health and letter was obtained with Ref. No.:ACIPH-MPH/026/12. Official letter of cooperation was submitted to respective health facilities. The aim of the study, the confidentiality, and the right to withdraw at any time without facing any consequences was explained to each participant at the 
time of recruitment. Written informed consent was obtained from each participant before enrollment to the study.

\section{Consent for publication}

Not applicable.

\section{Availability of data and materials}

The datasets used and/or analyzed during this study are available from the corresponding author on reasonable request.

\section{Funding}

Not applicable.

\section{Authors' information}

TH is Monitoring and Evaluation Officer at Center for Disease Control and Prevention, Woliso Town, Oromia, Ethiopia. HG is associate professor, public health expert, and instructor at Addis Continental Institute of Public Health, Addis Ababa, Ethiopia. She has many publications on quantitative and qualitative researches on international journals.

\section{Competing interests:}

Authors declare no conflict of interest.

\section{Author's contributions}

TH conceived and designed the study, data extraction, performed analysis, interpretation of data, and manuscript preparation. HG critically reviewed the full proposal, modified the study design, and reviewed the manuscript.

\section{Acknowledgements}

We are grateful to the data collectors for their efforts throughout data collection. We also thank study participants in Woliso Town Health Facilities as well as Woliso Town health facility staffs and Woliso 
Town Health office. We would like to thank Addis Continental Institute of Public Health for their cooperation during the study time.

\section{References}

1. The DHS Program. Federal Democratic Republic of Ethiopia, Demographic and Health Survey 2016. Ethiopia: Central Statistical Agency Addis Ababa; 2017.

2. Federal Ministry of Health Ethiopia (FMOH). National Comprehensive Care and Treatment guideline for Implementation. 2018.

3. Federal Ministry of Health Ethiopia (FMOH). National HIV Counseling and Testing Training Manual. 2018.

4. Federal Ministry of Health Ethiopia (FMOH). Partner and Family Based Index Case HIV Testing Service Training Manual. 2018.

5. Ahmed S, Sabelli RA, Simon K, Rosenberg NE, Kavuta E, Harawa M, et al. Index case finding facilitates identification and linkage to care of children and young persons living with HIV/AIDS in Malawi. Trop Med Int Health. 2017;22(8):1021-9.

6. Simon KR, Flick RJ, Kim MH, Sabelli RA, Tembo T, Phelps BR, et al. Family Testing: An Index Case Finding Strategy to Close the Gaps in Pediatric HIV Diagnosis. J Acquir Immune Defic Syndr. 2018 Aug 15;78 Suppl 2:S88-97.

7. Joseph Davey D, Wall KM, Serrao C, Prins M, Feinberg M, Mtonjana N, et al. HIV Positivity and Referral to Treatment Following Testing of Partners and Children of PLHIV Index Patients in Public Sector Facilities in South Africa. J Acquir Immune Defic Syndr. 2019 Aug 1;81(4):365-70.

8. Joore IK, Twisk DE, Vanrolleghem AM, de Ridder M, Geerlings SE, van Bergen JEAM, et al. The need to scale up HIV indicator condition-guided testing for early case-finding: a case-control study in primary care. BMC Fam Pract. 2016;17(1):161. 17(.

9. Tafuma TA, Mahachi N, Dziwa C, Marowa P, Moga T, Chimbidzikai T, et al. Time taken to link newly identified HIV positive clients to care following a home-base index case HIV testing: Experience from two provinces in Zimbabwe. PLoS ONE. 2018;13(8):e0201018.

10. Dalal S, Johnson C, Fonner V, Kennedy CE, Siegfried N, Figueroa C, et al. Improving HIV test uptake and case finding with assisted partner notification services. AIDS. 2017;24(13):1867-76. 31(.

11. Katbi M, Adegboye A, Adedoyin A, Yunusa F, Kayode G, Bello M, et al. Effect of clients Strategic Index Case Testing on community-based detection of HIV infections (STRICT study). International Journal of Infectious Diseases [Internet]. 2018 Sep 1 [cited 2019 Jun 27];74:54-60. Available from: https://www.ijidonline.com/article/S1201-9712(18)34453-9/abstract.

12. Lasry A, Medley A, Behel S, Mujawar MI, Cain M, Diekman ST, et al. Scaling Up Testing for Human Immunodeficiency Virus Infection Among Contacts of Index Patients - 20 Countries, 2016-2018. MMWR Morb Mortal Wkly Rep. 2019 May;31(21):474-7. 68(. 
13. Myers RS, Feldacker C, Cesár F, Paredes Z, Augusto G, Muluana C, et al. Acceptability and Effectiveness of Assisted Human Immunodeficiency Virus Partner Services in Mozambique: Results From a Pilot Program in a Public, Urban Clinic. Sex Transm Dis. 2016;43(11):690-5.

14. Wagner AD, O’Malley G, Firdawsi O, Mugo C, Njuguna IN, Maleche-Obimbo E, et al. Brief Report: Disclosure, Consent, Opportunity Costs, and Inaccurate Risk Assessment Deter Pediatric HIV Testing: A Mixed-Methods Study. J Acquir Immune Defic Syndr. 2018;01(4):393-9. 77(.

15. Kamanga G, Brown L, Jawati P, Chiwanda D, Nyirenda N. Maximizing HIV partner notification opportunities for index patients and their sexual partners in Malawi. Malawi Med J [Internet]. 2015 Dec [cited 2019 Jul 3];27(4):140-4. Available from: https://www.ncbi.nlm.nih.gov/pmc/articles/PMC4761705/.

16. Barro M, Sanogo B, Ouermi AS, Zio BR, Ouattara ABI, Nacro B. Acceptability of children's testing for HIV infection during routine care activities in the Pediatrics Department of Sourô Sanou Teaching Hospital in Bobo-Dioulasso (Burkina Faso). Rev Epidemiol Sante Publique. 2018 Nov;66(6):363-7.

17. Rentz MF, Ruffner AH, Ancona RM, Hart KW, Kues JR, Barczak CM, et al. Pilot Integration of HIV Screening and Healthcare Settings with Multi- Component Social Network and Partner Testing for HIV Detection. Curr HIV Res. 2017 Nov 23;15(5):372-81.

18. Rayment M, Curtis H, Carne C, McClean H, Bell G, Estcourt C, et al. An effective strategy to diagnose HIV infection: findings from a national audit of HIV partner notification outcomes in sexual health and infectious disease clinics in the UK. Sex Transm Infect. 2017;93(2):94-9.

19. Kahabuka C, Plotkin M, Christensen A, Brown C, Njozi M, Kisendi R, et al. Addressing the First 90: A Highly Effective Partner Notification Approach Reaches Previously Undiagnosed Sexual Partners in Tanzania. AIDS Behav. 2017 Aug;21(8):2551-60.

20. Lewis Kulzer J, Penner JA, Marima R, Oyaro P, Oyanga AO, Shade SB, et al. Family model of HIV care and treatment: a retrospective study in Kenya. J Int AIDS Soc. 2012 Feb 22;15(1):8.

21. Mahachi N, Muchedzi A, Tafuma TA, Mawora P, Kariuki L, Semo B-W, et al. Sustained high HIV casefinding through index testing and partner notification services: experiences from three provinces in Zimbabwe. J Int AIDS Soc. 2019 Jul;22 Suppl 3:e25321.

22. Technau K-G, Kalk E, Coovadia A, Black V, Pickerill S, Mellins CA, et al. Timing of maternal HIV testing and uptake of prevention of mother-to-child transmission interventions among women and their infected infants in Johannesburg, South Africa. J Acquir Immune Defic Syndr. 2014 Apr;15(5):e1708. 65(.

23. Musarandega R, Mutede B, Mahomva A, Nyamayaro W, Mushavi A, Lindan C, et al. Scaling up Pediatric HIV Testing by Incorporating Provider-Initiated HIV Testing Into all Child Health Services in Hurungwe District, Zimbabwe. J Acquir Immune Defic Syndr. 2018;01(1):78-85. 77(.

24. Abdurahman S, Seyoum B, Oljira L, Weldegebreal F. Factors affecting acceptance of provider-initiated HIV testing and counseling services among outpatient clients in selected health facilities in Harar Town, Eastern Ethiopia. HIV AIDS (Auckl). 2015;7:157-65. 
25. Beyene MB, Beyene HB. Predictors of Late HIV Diagnosis among Adult People Living with HIV/AIDS Who Undertake an Initial CD4 T Cell Evaluation, Northern Ethiopia: A Case-Control Study. PLoS ONE. 2015;10(10):e0140004.

26. Nikus Fido N, Aman M, Brihnu Z. HIV stigma and associated factors among antiretroviral treatment clients in Jimma town, Southwest Ethiopia. HIV AIDS (Auckl). 2016;8:183-93.

27. Desta WG, Sinishaw MA, Bizuneh KD. Factors Affecting Utilization of Voluntary HIV Counseling and Testing Services among Teachers in Awi Zone, Northwest Ethiopia. AIDS Res Treat. 2017;2017:9034282.

28. Medley AM, Hrapcak S, Golin RA, Dziuban EJ, Watts H, Siberry GK, et al. Strategies for Identifying and Linking HIV-Infected Infants, Children, and Adolescents to HIV Treatment Services in Resource Limited Settings. J Acquir Immune Defic Syndr. 2018 Aug 15;78 Suppl 2:S98-106.

29. Selvaraj K, Kumar AMV, Chawla S, Shringarpure KS, Thekkur P, Palanivel C, et al. Are partners of HIVinfected people being tested for HIV? A mixed-methods research from Gujarat, India. Public Health Action. 2017 Mar 21;7(1):46-54.

30. PEPFAR. PEPFAR 2020 Country Operational Plan Guidance for all PEPFAR Countries.. [Internet]. US Government; 2019. Available from: https://www.pepfar.net.

31. Wagner AD, Njuguna IN, Neary J, Omondi VO, Otieno VA, Babigumira J, et al. Financial Incentives to Increase Uptake of Pediatric HIV Testing (FIT): study protocol for a randomised controlled trial in Kenya. BMJ Open [Internet]. 2018 Oct 3 [cited 2019 Jul 3];8(10). Available from: https://www.ncbi.nlm.nih.gov/pmc/articles/PMC6194484/.

32. Hampanda KM, Nimz AM, Abuogi LL. Barriers to uptake of early infant HIV testing in Zambia: the role of intimate partner violence and HIV status disclosure within couples. AIDS Res Ther. $2017 \mathrm{Mar}$ 21;14(1):17.

33. Vasquez AL, Errea RA, Hoces D, Echevarria J, González-Lagos E, Gotuzzo E. Missed opportunities for HIV control: Gaps in HIV testing for partners of people living with HIV in Lima, Peru. PLoS ONE. 2017;12(8):e0181412.

34. Abtew S, Awoke W, Asrat A. Acceptability of provider-initiated HIV testing as an intervention for prevention of mother to child transmission of HIV and associated factors among pregnant women attending at Public Health Facilities in Assosa town, Northwest Ethiopia. BMC Res Notes. 2015 Nov 9;8:661.

35. Gizaw R, Gebremdhin S. Acceptance of HIV Counseling and Testing among Antenatal Clinic Attendees in Southern Ethiopia. Ethiop J Health Sci. 2018 Jul;28(4):413-22.

36. Lemu YK, Koricha ZB, Gebretsadik LA, Roro AG. Predictors of refusal of provider initiated HIV testing among clients visiting adult outpatient departments in Jimma town, Oromia Region, Ethiopia: unmatched case control study. HIV AIDS (Auckl). 2012;4:103-15.

37. Garcia de Olalla P, Molas E, Barberà MJ, Martín S, Arellano E, Gosch M, et al. Effectiveness of a pilot partner notification program for new HIV cases in Barcelona, Spain. PLoS ONE. 2015;10(4):e0121536. 
38. Murray A, Hussen SA, Toledo L, Thomas-Seaton L, Gillespie S, Graves C, et al. Optimizing Community-Based HIV Testing and Linkage to Care for Young Persons in Metropolitan Atlanta. AIDS Patient Care STDS. 2018;32(6):234-40.

39. Free encyclopidia. LixaShawaaElevation2, Total37, 878Time. Woliso Town, Wikipedia, topography, history and demography [Internet]. 2012 [cited 2019 Oct 27]. Available from: https://en.wikipedia.org/wiki/Waliso.

40. Dean AG, Sullivan KM, Soe MM. OpenEpi. Open Source Epidemiologic Statistics for Public Health, Version. www.OpenEpi.com. 2013.

41. Gebremedhin KB, Tian B, Tang C, Zhang X, Yisma E, Wang H. Factors associated with acceptance of provider-initiated HIV testing and counseling among pregnant women in Ethiopia. Patient Prefer Adherence. 2018;12:183-91.

42. Okechukwu AA, Ekop E, Ndukwe CD, Olateju KE. Acceptance of provider-initiated testing and counseling for HIV infection by caregivers in a tertiary health institution in Abuja, Nigeria: a cross sectional study. Pan Afr Med J. 2016;24:245.

43. Gebresillassie BM, Emiru YK, Erku DA, Mersha AG, Mekuria AB, Ayele AA, et al. Utilization of ProviderInitiated HIV Testing and Counseling as an Intervention for PMTCT Services Among Pregnant Women Attending Antenatal Clinic in a Teaching Hospital in Ethiopia. Front Public Health. 2019;7:205.

44. Atnafu Gebeyehu N, Yeshambel Wassie A, Abebe Gelaw K, Acceptance Of HIV, Testing And Associated Factors Among Pregnant Women Attending Antenatal Care. In Gunino Health Center, Southern Ethiopia 2019: An Institutional Based Cross-Sectional Study. HIV AIDS (Auckl). 2019;11:333-41.

45. 10.1080/09540121.2014.882489

Penfold S, Simms V, Downing J, Powell RA, Mwangi-Powell F, Namisango E, et al. The HIV basic care package: where is it available and who receives it? Findings from a mixed methods evaluation in Kenya and Uganda. AIDS Care [Internet]. 2014 Sep 2 [cited 2020 Jan 29];26(9):1155-63. Available from: https://doi.org/10.1080/09540121.2014.882489. 